\title{
BIM technologies' effect on transformation of a property life cycle
}

\author{
Yulia Boriskina $^{1, *}$ \\ ${ }^{1}$ Moscow State University of Civil Engineering, Yaroslavskoe shosse, 26, Moscow, 129337, Russia
}

\begin{abstract}
Property life cycle management is exposed to greater changes under impact of new BIM technologies and increasing demand for environmental approach. Many new technologies which BIM comprises, such as laser scanning, augmented reality, automate construction, distant access, renewable energy sources, affect management issues of project management leading to higher efficiency and environment protection via using greater cost predictability, improved schedule, optimized design, better coordination, and reduced energy and water consumption. Property life cycle management using BIM methods has priority over traditional management approach at each project stage, which generally leads to the extension of the life cycle and the construction of buildings with more environmentally friendly characteristics. The BIM management process affects all project parties. The article offers a special table which indicates changes for each participant: investor, developer, bank, designer, construction contractor, broker, tenant, project team, and re-conception team. Despite some controversial issues, like high costs and advanced skills of project participants, BIM management will be used by more developers, bringing economical and environmental efficiency for prolonged property life cycle.
\end{abstract}

\section{Introduction}

Global trends are making construction projects more and more complex, while advances in technology help industry professionals work more efficiently and effectively, even improving environmental performance. That is why leading developers are applying BIM technologies [1].

One of the construction project peculiarities is that it involves many parties and needs very precise management. In this relation BIM technologies are very much at hand, they help to reach high standards of a construction project execution [2]. BIM technologies provide coordination and allow including as many details and options as possible at the project design stage. Besides, BIM facilitates maintenance execution via proper work of engineering systems. All this prolongs life cycle period and lowers costs, allows performing effective environmental planning, making such properties more attractive for investors.

Nowadays, when competition in development is so high any management methods that lead to lower costs or demonstrate property's advantages, including environmental ones, are

*Correponding author: jivolga@mail.ru 
in high demand. Appearance of such technologies as BIM transform life cycle management and approach to resources consumption: developer is not just operating each stage, he has now more power to change the life cycle stages, define specific or outstanding characteristics and to know exact consequences of any changes in advance. Property life cycle management is now a more multi-processing and integral complex as ever before.

\section{BIM technologies and methods}

BIM is an abbreviation for Building Information Modeling.

BIM is and intelligent model-based process that connects project professionals so that they can more efficiently design, build and operate buildings and infrastructure. With BIM designers create digital 3-D model that include data associated with physical and functional characteristics. BIM allows engineers, architects and contractors to collaborate on coordinateв models, giving each of them better insight into how their work fits in into entire project, ultimately helping them to work more efficiently.

The data in a model defines the design elements and establishes behavior and relationship between model components. So, when an element in a model is changed, every view is updated with a new change appearing in section, elevation and sheet viewers. This includes environmental planning e.g. for energy and water consumption.

Developer can use information in the model before the building is built, get faster buying and approvals with realistic visualizations. BIM can wade design intent to the field and what is most important it can retain model intelligence from concept to construction.

BIM provides insight into design constructability, improving the efficiency and effectiveness of construction stage and also providing a better understanding of future operations and maintenance. Furthermore, managing projects with BIM facilitates for developer to incorporate more features of green buildings, such as minimizing household energy consumption, conserving household water, using disposals to dispose of waste, increasing recycling. Owners can use BIM for predictive maintenance, asset tracking, facilities management, and for future renovation or deconstruction projects. When one works with BIM he experiences reduced project risks, improved timelines and cost savings, better project outcomes and of course benefits from land sustainable energy technologies and green architecture. And the power of BIM is growing with Cloud-connected technologies [3], that let project teams and designers work together in all new ways. Driven by global trends development-and-construction industry is in a time of transformation. Businesses that want to win more work, deliver projects more efficiently and design better buildings need a powerful solution and that solution is BIM.

BIM impacts technological and management issues, improving the processes via such technologies as sensors, laser scanning, augmented reality, mobile devices, virtual reality, automate construction, distant access, renewable energy sources and many others.

Among technological effects one can mention the following ones: sophisticated lightening, energy consumption [4], structural integrity, long-lasting materials. Sustainable design with BIM helps to integrate those technologies as a part of environmental planning.

As to management effects BIM optimizes the following issues: greater cost predictability; improved schedule; fewer errors; optimized design; better understanding; reduce coordination issues; documentation; minimize change orders [5]. 


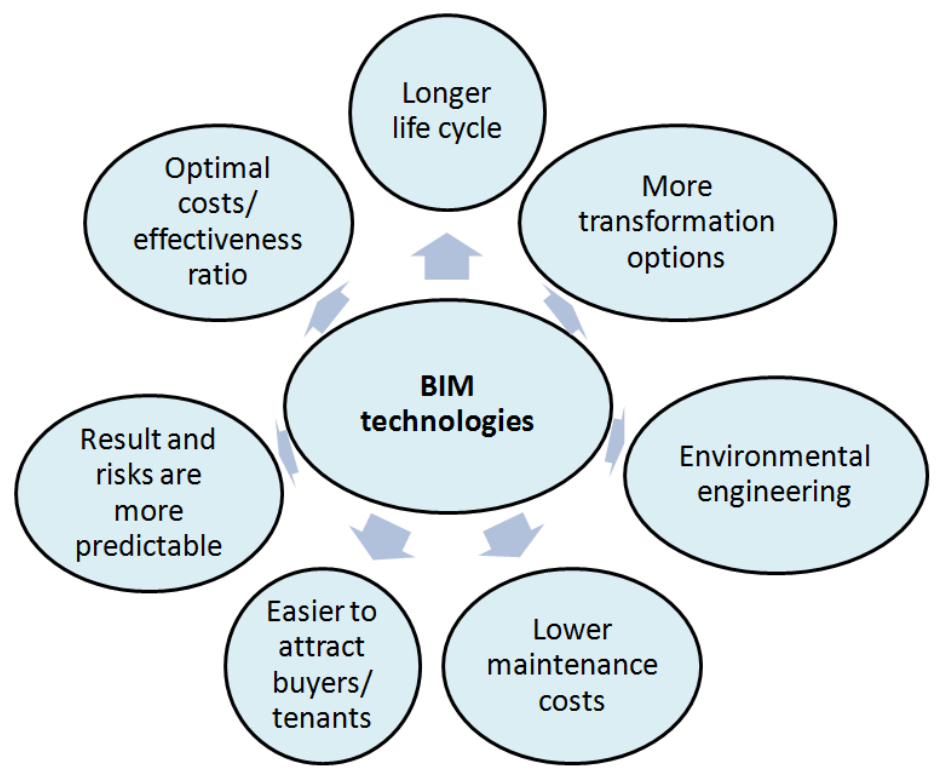

Fig. 1. BIM technologies advantages for a property construction project management.

Software companies eagerly develop new programs and functions for BIM technologies, popular ones are: AutoCAD, Revit, ArchiCAD, ZWCAD [6-8].

\section{Results}

New technologies lead to transformation in management approaches. Property life cycle management using BIM methods has priority over traditional management approach in several ways:

- extended life cycle. That means that for a longer period developer gains cash flow, or owner uses the building.

- more options at disposal stage: the BIM project can include several variants of redesigning, re-concepting the property, or even re-using of materials and parts of the building for new projects. What is important this multi-variety is achieved by the most efficient way, which can be chosen by developer at the designing stage.

- low maintenance costs [9].

Business planning. That is when it is important for developer to choose the proper management approach. Costs are not high for this stage, but it is the timing of property life cycle and priorities that matter here. Designing. For now BIM designing costs are higher comparing to traditional designing, but this is the stage where all the main advantages are created - software and experts are expensive. Constructing. At the stage of constructing expenses grow mostly because of modern (sometimes unique) construction technologies and materials, providing e.g. energy efficiency or future transformation possibilities.

Using and maintaining. This is where developer and investor can totally enjoy the benefits of using BIM. At this stage costs are much lower comparing to properties with traditional designing, efficient buildings are more attractive to tenants and have higher rent rates. Besides, the building can be used without any changes or with little changes for a longer period, it needs less reparations thus supporting sustainable development. Disposal. The idea of life cycle management is to foresee the future of a building, not just to take advantages from the operating period. And again, BIM is an excellent instrument for minimizing costs and maximizing options at this stage. 


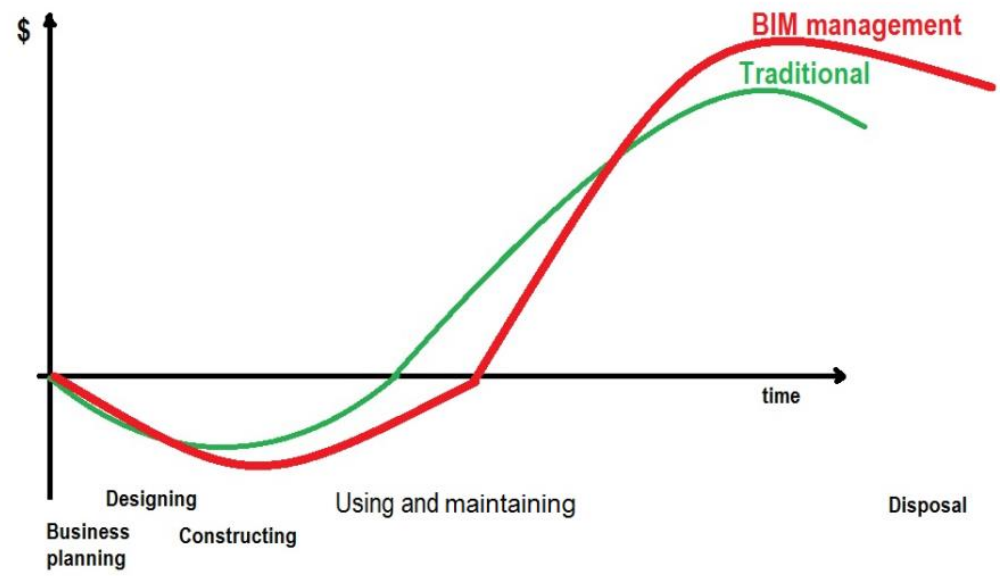

Fig. 2. Life cycle management of traditional and BIM designed Building.

Table 1. The effect of BIM technologies for the main property project participants.

\begin{tabular}{|l|l|}
\hline Participant & Effect \\
\hline Investor & $\begin{array}{l}\text { Before launching a project developer needs to convince an Investor to } \\
\text { participate in it. Investors are not always development and construction experts, so } \\
\text { for them any kind of visualizing is definitely a plus and developer has a wider choice } \\
\text { of investment partners. Besides, all investors are very well aware that construction } \\
\text { has numerous risks and all mistakes are extremely expensive. BIM allows seeing } \\
\text { the consequences and risks of any changes or mistakes beforehand, helping to save } \\
\text { money and time. }\end{array}$ \\
\hline Developer & $\begin{array}{l}\text { The distance between idea and what developer gets as result minimizes. BIM } \\
\text { can show several scenarios for multifunctional usage, maintenance, disposal (this } \\
\text { stage is very often underestimated. But if the building is situated in a tense buildings' } \\
\text { neighborhood with no place for cranes to explode the property is usually the } \\
\text { cheapest way to demolish it. Then developer can select suitable constructive } \\
\text { structure). It is much easier to adapt to new legislation and technical regulations - } \\
\text { instead of starting all over again, some elements are to be entered and many other } \\
\text { change automatically. Besides, when situation on the market changes project can be } \\
\text { adopted to new outcomes. Even functionality can be changed, but instead of } \\
\text { reconstructing the whole building some inside replanning work will be enough. } \\
\text { Using BIM technologies makes developer more compatible. }\end{array}$ \\
\hline Bank & $\begin{array}{l}\text { Using BIM technologies is much safer for the bank: less risks of mistakes, } \\
\text { multivariety of usage, less unpredicted situations, longer and more efficient property } \\
\text { maintenance. This should be a good reason for long-term partnership and even } \\
\text { discount rate. }\end{array}$ \\
\hline $\begin{array}{l}\text { It might seem that BIM designing is much harder for designer, but its vice versa. } \\
\text { contractor }\end{array}$ & $\begin{array}{l}\text { Of course it takes more time to create BIM design, but it is so much easier to } \\
\text { coordinate with other professionals and to make changes, which always present in } \\
\text { construction projects. } \\
\text { any necessary parameters and possibility to reflect an unexpected situation and waits } \\
\text { less time to get a backup plan. }\end{array}$ \\
\hline Designer
\end{tabular}




\begin{tabular}{|l|c|}
\hline Broker & $\begin{array}{c}\text { BIM technologies are a dream come true for brokers. Now they can offer a } \\
\text { visualized 3-D Smart-Model experience to potential buyers. 3-D glasses and tours } \\
\text { to an non-existing apartments are already helping to sell units. And there are good } \\
\text { reasons for a higher price: the model can confirm benefits of longer-lasting materials } \\
\text { and energy efficiency, show several day and night lightning scenarios. }\end{array}$ \\
\hline Tenant/ User & $\begin{array}{l}\text { When a building is energy effective and maintenance costs are low any tenant } \\
\text { or owner will be satisfied. He can also appreciate some well-thought details in } \\
\text { interior design or comfort elements. }\end{array}$ \\
\hline $\begin{array}{l}\text { Maintenance } \\
\text { team }\end{array}$ & $\begin{array}{l}\text { Engineering is an important part of BIM (sometimes moving lamps 50cm can } \\
\text { save 1-10\% of lightning energy consumption, ventilation cameras proper placement } \\
\text { can lower or higher the ceiling) Maintenance team gets integrated engineering } \\
\text { systems with excellent criteria. Unfortunately, very often maintenance companies } \\
\text { have to start with re-setting and tuning after contractor. With BIM they get a } \\
\text { property with better system or can also give recommendations at the designing stage. } \\
\text { Materials used for construction and interior design are implemented long- } \\
\text { lasting, resistant and sustainable - helping to operate the building. }\end{array}$ \\
\hline $\begin{array}{l}\text { BIM allow developer to find such a universal constructive structure that can be } \\
\text { easily adopted if he want to transfer property e.g. from fitness-gym to offices. } \\
\text { team }\end{array}$ & \begin{tabular}{l} 
anception \\
\hline
\end{tabular}
\end{tabular}

\section{Discussion}

Of course, using BIM at every property construction project has some controversial moments.

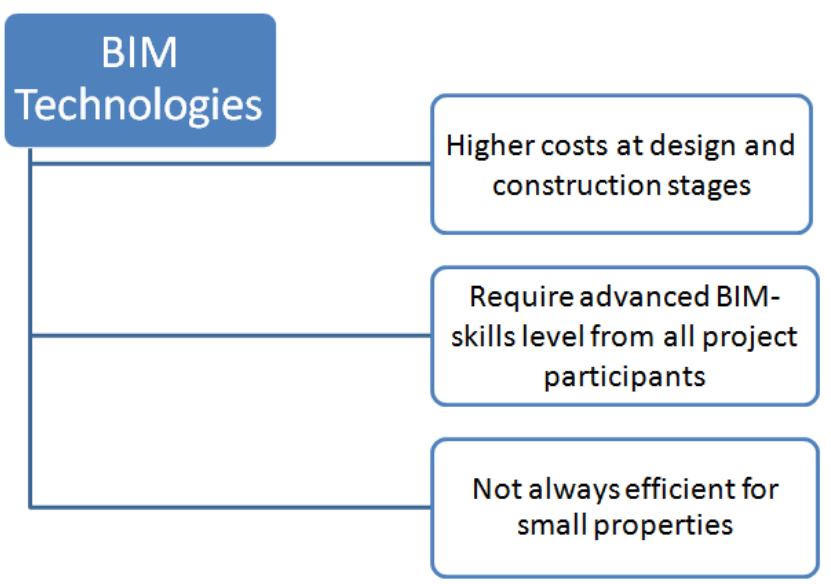

Fig. 3. Controversial issues of BIM technologies implementation for property projects management.

One of the serious drawbacks is that BIM software and experienced professionals are more expensive. Thus only big companies can afford to use them, applying them in numerous projects and dividing the costs, while for smaller companies it is harder to compete.

However, all construction professionals expect that after BIM becomes used more widely, the costs will decrease and developers will see the cost effectiveness of BIM much faster that will lead to every-day usage of BIM. For some countries with high costs of water or energy efficient buildings become priority in the long run. Furthermore, distant access function cuts some expenses even now: if is very often that architects, consultants and designers working on a construction project are from different countries (with lower wage rates or just more experienced ones) - they don't need to fly to general meetings as often as with traditional project management. 
Another matter of concern is that all project professionals should be advanced users of BIM programs. Sometimes a developer has to reject architects and contractors, with whom he has worked before if they don't fit into BIM project management standards. In some countries this narrows choice or sometimes even becomes a reason to hire a foreign part. And of course, project mangers working in a development company should be well experienced to set tasks, control, and coordinate using BIM approach.

It is fair to mention, that not all properties require BIM approach in life cycle management. There are many small buildings with simple functionality and standard wellknown life cycle. For those buildings project team experienced in BIM technologies is an overambition. Whereas for big complex buildings, with multifunctionality or for properties situated in developing areas of city downtown or, on the contrary, uptown BIM is the key to prolong the life cycle.

\section{Conclusion}

BIM - is an excellent instrument for life cycle management, it helps not only to create efficient buildings and decreases maintenance costs, but it also makes property life cycle longer, more predictable and sustainable.

BIM technologies are not to replace property life cycle management, but on the contrary, via sophisticated design and construction stages to facilitate management, to help indicating costs and benefits of environmental economy implementation.

Nowadays life cycle management and BIM technologies are different concepts, but they intervene each other so significantly, that may be in the nearest future BIM would become an essential part of property life cycle management.

However, at present, the main role is still played by developer. The major transformation nowadays is that project manager has to be a good BIM operator himself, setting high standards for other project participants. New technologies are offering wonderful options and it is important for developer to know how to apply them to manage property life cycle in the most efficient way. BIM is an excellent example of new multiuse technologies, which do not only upgrade project's coordination and efficiency but also preserve environment by applying sustainable design and environmental planning.

\section{References}

1. L. Ustinovichius, V. Popov, J. Cepurnaite, T. Vilutienè, C. Miedziałowski, Archives of Civil and Mechanical Engineering 18(4), 1136-1149 (2018)

2. Sh. Habibi, Energy and Buildings 153, 525-548 (2017)

3. S. Beazley, E. Heffernan, T.J. McCarthy, Energy Procedia 121, 57-64 (2017)

4. S. Eleftheriadis, D. Mumovic, P. Greening, Renewable and Sustainable Energy Reviews 67, 811-825 (2017)

5. M. Marzouk, Sh. Azab, M. Metawie, Journal of Cleaner Production 188, 217-226 (2018)

6. J. Lou, J. Xu, K. Wang, Procedia Engineering 174, 668-676 (2017)

7. T.O. Olawumi, D.W.M. Chan, Sustainable Cities and Society 40, 16-27 (2018)

8. Y. Yuan, J. Yuan, Procedia Engineering 15, 5323-5327 (2011)

9. J. Fountain, S. Langar, Automation in Construction 95, 107-117 (2018) 